\title{
O PROCESSO DE ENVELHECIMENTO E A NECESSIDADE DE INCLUSÃO (DIGITAL) DO IDOSO NO ÂMBITO ACADÊMICO
}

Diego Paes Ehmke; Universidade de Cruz Alta (UNICRUZ); diegopaes.ehmke@gmail.com Solange Beatriz Billig Garces; UNICRUZ; sbgarces@hotmail.com Rômulo José Barboza dos Santos; UNICRUZ; romullobarboza@hotmail.com Pâmela Fanfa Ribeiro Gonçalves; UNICRUZ; pfgoncalves2001@hotmail.com

\section{RESUMO}

Introdução: As manifestações fisiológicas do envelhecimento influenciam de forma direta nas habilidades motoras e psíquicas necessárias para se fazer uso dos dispositivos tecnológicos, os quais evoluem de maneira acelerada, sendo difícil acompanhar esta evolução em ritmo igual até mesmo para os mais jovens e já nascidos nesta geração digital. Objetivo: Investigar a relação entre o envelhecimento e a inclusão (digital) do idoso no âmbito acadêmico. Métodos: Trata-se de um recorte da dissertação em que um Estudo de Caso foi desenvolvido no contexto da UNICRUZ, que possuía 2.374 acadêmicos matriculados no ano de 2019, distribuídos em 20 Cursos de Graduação. A amostra foi composta por 30\% desta população, ou seja, 712 discentes, que responderam a Escala sobre Ageismo no Contexto Organizacional. Resultados: 56,9\% dos participantes afirmaram concordar totalmente que estudantes mais jovens compreendem e dominam melhor as tecnologias do que os mais velhos. Ainda, 47,1\% dos participantes concordaram que o envelhecimento afeta diretamente a produtividade nos estudos. Destarte, ficou evidente que uma das principais barreiras de entrada de estudantes idosos na universidade, é o desconhecimento e/ou a inabilidade em operar aparelhos tecnológicos, seja o celular, o tablet ou o computador. Conclusão: Atualmente é imprescindível o acesso à Tecnologia Digital e aos meios de comunicação, quer seja para fins acadêmicos, de trabalho, comunicação e/ou socialização. Portanto, há a necessidade de apoio por parte da Universidade no desenvolvimento de atividades que possibilitem o idoso ser capaz de utilizar tais dispositivos, para que este se sinta devidamente incluído no âmbito acadêmico.

Palavras-chave: Idoso; Inclusão; Tecnologia. 